\title{
Disruption and the Changing Concept of Leadership
}

\author{
Prof Dr M S S El Namaki, \\ School of Management, Victoria University, Switzerland
}

\begin{abstract}
Leadership is a catch all concept and the subject attracts intensive attention. Yet the concept, as it stands today, is obsolete. The prime parameters of people and tasks have lost content with people performance parameters going through palpable change and the fundamentals of the task seriously disrupted. Those developments are rendering concepts of leadership in their current professional and conceptual framework, blurred. Gamely and fashion prone colourful presentation of "leadership" are taking over. A serious search into the heart and soul of leadership and a formulation of building blocks is, therefore, needed. It should be serious and it should be conceptual and operationally cogent.
\end{abstract}

The following article provides an attempt at that. The article starts with a proposition stating that contemporary multi-functional disruptive change is leading to an expression of leadership that is closely associated with individual perspective and exercise of control. Perspective and control take the issue out of the traditional single track focus on the leader's behaviour or traits to the broader context of the leader, as an individual, the followers, as players and events, as disruptive forces. The article further defines perspective in terms of vision and desire to achieve. It also defines control in terms of locus, and management of self. A propensity to lead is derived from the analysis. Case evidence compliments the analysis.

The article is of benefit into breathing fresh air into what is rapidly becoming a stale conceptual and professional arena. The two parameters, once converted into an operational model, could, help the process of management of today's turbulent businesses.

Paper Type: Conceptual Paper

Keywords: Leadership; Contemporary Trends; Propensity to Lead; Disruptive Change 


\section{The premises}

Most contemporary concepts of leadership entertain the premise that a leader is an individual who is able to convince others to follow him towards an identified goal. It is a process whereby an individual induces "followers" to work towards an individual or a group end result. Creating conviction and fellowship could be explained in terms of leadership theories and approaches, namely contingency theory (Fiedler, 1958), situational approach (Blanchard et al., 1993), path-goal theory (House, 1996), transformational leadership (Avolio et al, 2009), trait, style, and skills approaches (Northouse, 2013),. Historical, cultural, and technological change have resulted in a shift of power from leaders to followers. There is little objective evidence to confirm that decade's long massive and expensive effort at leadership development has paid off (Kellerman, 2012). It all, unfortunately, adds up to a rather blurred whole that is, at times, divorced from reality and could, at other times, border on the irrelevant (Henman, 2017). It is becoming an industry feeding upon itself.

Conceptual blur is not only the outcome of the great diversity of schools of thought but also the very fundamental shift in the building stones of the concept itself. All three building stones, the leader, the followers and the environment have been changing content, relationship and boundaries. Disruption is setting in. The need is there for a gust of fresh air within the leadership arena.

\section{The proposition: determinants of leadership within a disrupted environment}

It is the author's contention that demonstration of leadership within today's disrupted environment depends on the development of a perspective and the exercise of control. An individual assumes leadership within a given context because of his ability to conceive a perspective and complement that with a measure of control. Perspective conveys an awareness of the situation, the intricacies of the ongoing process and the ultimate collective goal. Control connotes a realization of the role of others, the interaction among the players, the spectre of the force field and the degree of ultimate achievement. Both blend in order to lead to the assumption of leadership, the expression of fellowship and the ultimate joint trek towards a final goal. All within today's overly disrupted environments.

But what constitutes disruption?

Dobbs et al. (2014) points to three prime sources of disruption: shift in economic locus, rapid technology change and the information revolution. A distinct shift in the locus of economic activity to emerging markets has been taking place for some time now. Those "emerging markets are going through simultaneous industrial and urban revolutions, shifting the centre of the world economy east and south at a speed never experienced before. Then there is the acceleration in the scope, scale, penetration and economic impact of novel technologies and the resultant shorter life cycles of companies, processes products and, leaders. And third, there is the accelerating connectivity through information i.e. data and communication and a parallel enhancement of trade, finance and knowledge. The result is a state of discontinuity of longer term trends and a somewhat blurred picture of the horizon. And an imperative shift in leadership as a conceptual and operational process.

International Journal of Management and Applied Research, 2017, Vol. 4, No. 2 


\section{Determinant one: Perspective}

Perspective is a mental view or outlook. Perspective represents a state induced by individual experience, ability to identify the core from the periphery as well as a strong element of cognition. Studies (Fiedler, 1958; Wynne, 1982) show that leadership effectiveness correlates significantly with his or her ability to perceive accurately the differences among his subordinates.

A sound perspective is essential for a process of leadership.

\subsection{Vision}

A vision is a mental perception of the kind of environment an individual or an organization aspires to create within a broad time horizon and the underlying conditions for the actualization of this perception (El Namaki, 1992). Visions are inherent in the process of direction setting or the identification of something in the future, a vision, often the distant future, and the development of a strategy for getting there. Visions require commitment and total immersion with time, people and structures seen in terms of their relevance to their existence (Collins, 2015).

Leaders perceive their visions and do not ask themselves whether they have one.

\subsection{Motivation to achieve}

Achievement motivation connotes an urge to accomplish; to master things, people, or ideas and to attain high standards. Its cognitive roots lie in human motivation theories where individuals are assumed to have one of three main driving motivators: achievement, affiliation and or power. The motivation - to achieve arises when an individual knows that he is responsible for the outcome of an effort, when he anticipates explicit knowledge of the results that will define his success or failure, and when there is some degree of risk, i.e., some uncertainty about the outcome of his effort. The goal of achievement oriented activity is to succeed, to perform well in relation to a standard of excellence or in comparison to competitors (McClelland 1961).

A leadership context dictates a high measure of motivation to achieve.

\section{Determinant two: Control}

Control, for people and organizations, connotes measuring outcomes against a predetermined goal, or a probable potential, or both. The process assumes setting of goals, scanning of outcomes, identifying areas of non fulfilment and introducing corrective action. This implies an ability by the individual, the leader, to go all the way from setting desired end results to checking progress and inducing course adjustment.

To do that one should be able to manage oneself within a proper locus domain.

\subsection{Managing self}

Managing self is a process whereby an individual sets a context for his performance and develops modes for performance monitor and adjustment (Drucker, 2005). The concept rests on the argument that those who have achieved, in a managerial sense,

International Journal of Management and Applied Research, 2017, Vol. 4, No. 2 
have always managed themselves. Several key "probes" some intrinsic and some environmental provide the context and the monitor framework. Intrinsic include questions related to the strengths and weaknesses of the individual in question as well his level of performance. To the environmental belongs the individual's view of his contribution to this environment and responsibility for the associated relationships. The essence is that a leader should possess a deep understanding of what is going on within himself and learn how to manage that when it comes to interaction with his environment (El Namaki, 2014).

\subsection{Locus of control}

Locus of control is the degree to which individuals are able to attribute the decisions that they take to their own reasoning and decision making competencies. It could be internal or external. An internal locus relates the outcome of a decision making process to his own reasoning. An external locus relates this outcome to forces within the environment. Individuals with a strong internal locus of control believe in their ability to influence events and formulate ultimate decisions. People with a strong external locus of control tend to relate their decisions to forces beyond their own decision making competencies (Rotter, 1954).

Leadership studies (e.g. De Hoogh and Den Hartog, 2009; Meissner and Wulf, 2016) indicated that individuals in top management tend to have a high measure of internal locus and this has, obviously, far reaching implications to the conduct of leadership.

\section{Case examples}

\subsection{Case one: Wanda and Wang Jianlin; bold perspective and tight control}

Wanda Group is a Chinese conglomerate with roots in the real estate industry. Dalian Wanda has risen from modest beginning in the real estate industry to a global conglomerate with assets in the entertainment, property and sports industries (Flannery, 2017). A leadership that combined sharp perspective and tight control triggered the process.

Wanda sought synergy within the cinema and movie industry and acquired in 2012, the U.S.-based cinema operator AMC Theatres against $\$ 2.6$ billion, probably the largest Chinese acquisition of an American company to date. The acquisition made Wanda Cinemas the world's largest cinema operator (The Economist, 2015) and gave it, by 2016, ownership of approximately $6 \%$ of all commercial movie screens in China, and about $13 \%$ in the U.S. AMC appear to serve as the first element of a vertical integration cum synergy strategy connoting financing, production and distribution of Hollywood style films for the global market. By 2020, Dalian Wanda aims to become global entertainment colossus reaching, annual revenue of $\$ 100$ million by 2020 (Dalian Wanda Group, 2014).

Wanda is driven by Wang Jianlin, an exceptional business leader who joined the People's Liberation Army at the age of 15 and conceived, 17 years later, a business vision. His leadership behaviour seems to be built around a dynamic vision, a keen desire to achieve, a balance between internal and external control and a high measure

International Journal of Management and Applied Research, 2017, Vol. 4, No. 2 
of self-management. Mr. Wang's ambition and business acumen lie at the heart of Dalian Wanda's growth.

\subsection{Case two: Blackberry and Mike Lazaridis; fading perspective and failed control}

Blackberry, a mobile device, was introduced, in 1999, by Canadian Research in Motion (RIM), a consulting firm. The device was an instant success due to its push email," and a QWERTY keyboard (Woodham, 2016). Mike Lazaridis, the founder and CEO for the greatest part of the company's life, possessed the perspective and exercised the control that lead to Blackberry's initial success. He, however, failed, years later, to conceive a new perspective compatible with technology and market shifts. Production came to a halt in 2016.

Blackberry's first devices acquired massive following among business executives and government officials. Revenues grew as it continued to expand functionality in the BlackBerry Enterprise Server (BES) and the BlackBerry OS. BlackBerry continued to expand and add new products until it ranked, in 2009, first in Fortune's 100 fastest growing companies. It also achieved in 2010 the largest market share (37.3\%) in the United States smartphone market and its global user base stood at 36 million subscribers (Woodham, 2016).

Mike Lazaridis, the founder and CEO for the greatest part of the company s life, failed to grasp the potential impact of the touch screen devices that were introduced by competitors as Apple and Google. He opposed the launch of a Blackberry touch screen device arguing, strongly, in favour of the keyboard variety. When BlackBerry finally did launch a touchscreen device, it was seen as a poor imitation of the iPhone. A stark disparity in vision explains the situation. Mr. Lazaridis saw Blackberry devices as fancy, e-mail-enabled mobile phones while Apple and Google envisioned powerful mobile computers with wider functional competencies.

\subsection{Case three: IKEA and ingvar kamprad; long term perspective and congruent control}

IKEA is known for its modern appliance and furniture architecture as well as simple interior designs. In 1956, IKEA revolutionized the furniture industry by introducing "flat pack", an approach whereby the customer is asked to assemble the purchased products (Lewis, 2004). Cost control, attention to operational details, and continuous product development are landmarks of the company's culture and operations.

IKEA's success could be attributed to the founder: Ingvar Kamprad who conceived IKEA's vision and developed the company's concept of business. He ran a complex corporate structure that included charitable, retail and franchise arms until he retired in 2013. When taking his company public he decided that the stock market was not an option for IKEA. "I knew that only a long-term perspective could secure our growth plans, and I didn't want IKEA to become dependent on financial institutions." (Ingvar Kamprad, cited in Loudenback, 2015)

International Journal of Management and Applied Research, 2017, Vol. 4, No. 2 
Kamprad is a textbook case of a leader who developed the right long term perspective and exercised a proper mix of controls. He is known for vision, egalitarianism and constant search for better ways to do things.

The outcome: the concept of the Propensity to Lead.

A blend of perspective and control could lead to what we may term the Propensity to Lead or a measure of an individual's ability to perform a leadership function. High propensity is synonymous with a penetrative perspective and conducive control. An individual with a high propensity to lead is most likely to be able to:

- Conceive a dynamic vision that mirrors the goals and aspirations of the constituents, reflects environmental disruptions and is derived from a sense of direction.

- Have high achievement motivation coefficient allowing for a desire to excel, a setting of ambitious goals, a measurement of performance as well as an openness to feed back.

- Maintain a balance between internal and external controls thus allowing external forces to have an impact without undermining intrinsic judgment.

- Managing self in a manner conducive to the conduct of the leadership function and, equally, the expectations of his followers i.e. keenly aware of his strengths and weaknesses, is assuming responsibility for relationships and have an eye to others expectations.

One could suggest that drivers of complex organizations as Wanda and IKEA belong to what we may term a high propensity to lead bracket.

\section{Summary and Conclusions}

Leadership is a catch all concept and the subject attracts intensive attention. Yet the concept, as it stands today, is obsolete. The prime parameters of people and tasks have lost content with people performance parameters going through palpable change and the fundamentals of the task seriously disrupted. Those developments are rendering concepts of leadership in their current professional and conceptual framework, blurred. Gamely and fashion prone colourful presentation of "leadership" are taking over. A serious search into the heart and soul of leadership and a formulation of building blocks is, therefore, needed. It should be serious and it should be conceptual and operationally cogent.

This article provides an attempt at that. The article starts with a critique of current concepts and proceeds to suggest a framework that accommodates contemporary disruptions. Two parameters are identified as essential to a leadership function under contemporary conditions of disruption: perspective and control. Perspective and control take the issue out of the traditional single track focus on the leader's behaviour or traits to the broader context of the leader, as an individual, the followers, as players and the event, as a disruptive environmental force. The article further defines perspective in terms of vision and desire to achieve. It also defines control in terms of locus, and management of self. Analysis of supportive case evidence drawn from

International Journal of Management and Applied Research, 2017, Vol. 4, No. 2 
Wanda, Blackberry and IKEA leads to the introduction of the Propensity to Lead or a measure of the attributes of those two determinants.

\section{References}

1. Avolio B, Walumbwa F, Weber T, (2009), "Leadership: Current Theories, Research, and Future Directions", Annual Review of Psychology, Vol. 60, pp. 421449. https://doi.org/10.1146/annurev.psych.60.110707.163621

2. Blanchard, K. H., Zigarmi, D., and Nelson, R. B. (1993), "Situational leadership ${ }^{\circledR}$ after 25 years: A retrospective", Journal Of Leadership Studies, Vol. 1, No. 1, pp. 21-36. https://doi.org/10.1177/107179199300100104

3. Collins, J. (2001), Good to Great, London: Random House Business.

4. Dalian Wanda Group (2014), Group Profile, [Online] available from: https://www.wanda-group.com/corporate/ [accessed on 11 March 2017].

5. De Hoogh, A. B. and Den Hartog, D. N. (2009), "Neuroticism and locus of control as moderators of the relationships of charismatic and autocratic leadership with burnout", Journal Of Applied Psychology, Vol. 94, No. 4, pp. 1058-1067. https://doi.org/10.1037/a0016253

6. Dobbs, R.; Ramaswamy, S.; Stephenson, E. and Viguerie, S. P. (2014), "Management intuition for the next 50 years", McKinsey Quarterly, [Online] available from: http://www.mckinsey.com/business-functions/strategy-andcorporate-finance/our-insights/management-intuition-for-the-next-50-years [accessed on 11 March 2017].

7. Drucker, P. (2005), “Managing Oneself”, Harvard Business Review, Vol. 83, No. 1, pp. 100-109.

8. The Economist (2015), "Dalian Wanda: It's a Wanda-ful life", Economist, 14th Feb, [Online] available from:

http://www.economist.com/news/business/21643123-chinas-biggest-propertytycoon-wants-become-entertainment-colossus-its-wanda-ful-life [accessed on 11 March 2017].

9. El Namaki, M. S. S. (1992), “Creating a corporate vision”, Long Range Planning, Vol. 25, No. 6, pp. 25-29. https://doi.org/10.1016/0024-6301(92)90166-Y

10. El Namaki, M. S. S. (2014), “The Emerging Horizon”, in: Strategic Thinking for Turbulent Times, UK: Palgrave Macmillan, pp 167-186.

https://doi.org/10.1057/9781137414007_20

11. Fiedler, F. E. (1958), Leader Attitudes and Group Effectiveness, Urbana, IL: University of Illinois Press.

12. Flannery, R. (2017), "Entertainment Industry Prospects Best In Emerging Markets, Wanda's Wang Jianlin Tells Forbes China", Forbes, p. 8.

13. Henman, L. (2017), Leadership: Theories and Controversies, Henman Performance Group, [Online] available from: https://www.henmanperformancegroup.com/articles/Leadership-Theories.pdf [accessed on 11 March 2017].

International Journal of Management and Applied Research, 2017, Vol. 4, No. 2 
14. House, R. J. (1996), "Path-goal theory of leadership: Lessons, legacy, and a reformulated theory", The Leadership Quarterly, Vol. 7, No. 3, pp. 323-352. https://doi.org/10.1016/S1048-9843(96)90024-7

15. Kellerman B. (2012), The End of Leadership. New York: Harper Business.

16. Lewis, E. (2004), "Chapter 3: The E and the A of Ikea- Elmtaryd farm in Agunnaryd", In: Great Ikea: A Brand for All the People, London: Marshall Cavendish Limited, pp. 46-59.

17. Loudenback, T. (2015), "How IKEA founder Ingvar Kamprad became one of the richest self-made billionaires", Business Insider, [Online] available from: http://www.businessinsider.com/how-ikea-founder-ingvar-kamprad-became-abillionaire-2015-7 [accessed on 11 March 2017].

18. McClelland, D. (1961), The Achieving Society, New York: Free Press.

19. Meissner, P. and Wulf, T. (2016), "Debiasing illusion of control in individual judgment: The role of internal and external advice seeking", Review of Managerial Science, Vol. 10, No. 2, pp. 245-263. https://doi.org/10.1007/s11846014-0144-6

20. Northouse, P.G. (2013), Leadership: theory and practice. 6th ed. Thousand Oaks, CA: Sage.

21. Rotter, J. B. (1954), Social Learning and Clinical Psychology, New Jersey: Prentice-Hall.

22. Woodham, J. M. (2016), "BlackBerry", In: A Dictionary of Modern Design, 2 ed., Oxford: Oxford University Press.

https://doi.org/10.1093/acref/9780191762963.013.0882

23. Wynne, B. (1982), "Behavioral Science: Effective Application of Staff Expertise within Corporations", Interfaces, Vol. 12, No. 4, pp. 81-91.

https://doi.org/10.1287/inte.12.4.81

International Journal of Management and Applied Research, 2017, Vol. 4, No. 2 